\title{
How Unique Are Our Users? Part 2: Comparing Responses Regarding the Information-Seeking Habits of Education Faculty
}

\section{Sarah Robbins and Karen Rupp-Serrano}

\begin{abstract}
This follow-up study examines whether or not findings of single institution studies are applicable to other institutions by performing an institution-toinstitution comparison of the results obtained from an information-seeking behavior survey sent to education faculty at twenty research institutions. The results from this study corroborated what was found in the previous study conducted on the information-seeking behavior of engineering faculty in 2009. It indicates that general information about informationseeking behavior of faculty holds true across institutions, while information related to specific library services or facilities should be validated locally.
\end{abstract}

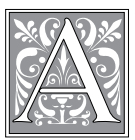

s budgets tighten across higher education, libraries are under greater scrutiny for their spending and are being held increasingly accountable for their contributions to the missions of their home institutions. As a result, librarians must astutely demonstrate their contributions to the teaching, research, and service of the university; one way to do this is through user surveys determining the value students and faculty place on library resources and services. The results of many of these studies are published in the professional literature; however, these published studies, often written by practitioners, usually focus on the situation at a single institution with little attention paid to the transferability of the findings to broader audiences. This means readers must determine for themselves how, if at all, the results apply to their situations. To promote a culture of evidence-based practice within librarianship, library practitioner-researchers need to develop studies and report results in a way that promotes educated consumption by their peers. It is costly to undertake user studies, so it is important to know what types of information about library users hold true from institution to institution and what types should be locally validated before taking action.

For the current study, identical user surveys related to the information-seeking behavior of education faculty were conducted at twenty research institutions. The researchers then examined the results by institution and compared the findings at other institutions included in the study

Sarah Robbins is Director of Public Relations \& Strategic Initiatives and Karen Rupp-Serrano is Director of Collection Development $\mathcal{E}$ Scholarly Communication, both at University of Oklahoma Libraries; e-mail: srobbins@ou.edu,krs@ou.edu. (C) 2013 Sarah Robbins and Karen Rupp-Serrano, AttributionNonCommercial (http://creativecommons.org/licenses/by-nc/3.0/) CC BY-NC 
to ascertain to what extent librarians can apply the findings of single institution research to their own situations. While we often think our situation and users are unique, are these beliefs grounded in reality?

\section{Background Information}

In the previous article discussing the uniqueness of users, the literature review focuses on practitioner-researchers in libraries, the nature of research in library and information studies, and user behavior studies and user satisfaction surveys at large. While a recap of the literature review in these areas is not necessary for the understanding of the current study, several articles have been published since the writing of the previous article that warrant mentioning and indicate that the topic is still relevant.

In a series on evidence-based librarianship 101, Virginia Wilson focuses an entire article on the importance of determining if and to what extent research findings are applicable to one's own situation. She delineates how practitioners can determine if presented evidence is applicable to their situation by considering the user groups, timeliness, cost, workplace politics for application, and the severity of the situation in need of a solution. ${ }^{1}$ She reminds practitioner-researchers that:

You will more likely find evidence that resembles your situation, but that needs to be replicated and validated at the local level.... It is worthwhile keeping in mind that if you go the route of validating the evidence you have found by replicating it at your level, the greater LIS community will benefit if you write up your efforts and find a way to disseminate the information. ${ }^{2}$

This emphasizes not only the importance of using research in practice but also the importance of sharing research results with a broad audience so others in the field benefit from the findings.
Ray Lyons recounts the plethora of issues surrounding the use of improper research methods and statistical analysis within the field. ${ }^{3}$ He specifically discusses convenience sampling, selection bias, and the problem of nondata. This article heightens awareness of common pitfalls found in the LIS literature and educates readers about the dangers of these issues when present in studies. An understanding of these limitations is important for practitioner-researchers who often use their home institutions, a sample of convenience, as the basis for their studies.

Echoing sentiments shared by Lyons, Greifendeder and Seadle discuss problems with the data gathering for a study about mystery shoppers as a way to evaluate reference services in an editorial for a recent issue of Library $\mathrm{Hi}$ Tech. ${ }^{4}$ The authors indicate that, while the researcher's findings may indeed be helpful to the institution, the limitations of the study should be communicated. They conclude:

The people who do the real disservice to the institutions they study are those who misrepresent the validity of their data and attempt to draw unsupportable conclusions based on those data. That can be avoided without trouble or expense. Avoiding useless results requires openness and transparency about how the data were gathered and a reasonable judgment that does not exaggerate what these data can possibly mean. ${ }^{5}$

This reiterates the importance of researchers clearly and accurately communicating their research methodologies and being honest about the limitations of the study. A clear understanding of a study's limitations as well as the methodology assists practitioners in determining if the findings might be relevant to their particular situation.

Lili Luo examines the role that the LIS research methods course plays in pre- 
paring practitioners to conduct research once they are in the workplace. ${ }^{6}$ Luo finds that the "majority of LIS practitioners did involve research at work" though it was primarily using existing research to solve problems or improve services rather than conducting original research. She also found that practitioners considered the research methods course helpful for evaluating research studies and applying them, improving services to patrons, and designing and implementing studies for gathering data to facilitate decision making or solve problems. These findings are encouraging for those who bemoan the state of LIS research and suggest that requiring LIS students to complete a research methods course as a part of their master's degree program might help to improve the quality of research studies published by practitioner-researchers.

\section{Methodology}

To test whether the findings of user studies conducted by researchers at a single library can be applied to other, similar libraries, the researchers conducted a user study of education faculty members at multiple institutions and compared institution-to-institution results. This methodology replicates a study conducted on engineering faculty in the fall of 2009 and is meant to test whether the findings of the initial study hold true in a different discipline. A separate paper presents the aggregated results of the information-seeking behaviors of education faculty based on the survey data.

The researchers surveyed education faculty members at twenty research institutions from across the United States. The 15-item survey consisted of demographic, open- and close-ended questions (see Appendix). The survey gathered both qualitative and quantitative data and was designed to take less than ten minutes to complete; all questions were optional. Responses were anonymous and confidential. The survey was derived from the surveys used by Robbins et al., Jankowska, and Cannon. ${ }^{7}$
In October 2010, an e-mail invitation to participate in an online survey was sent to approximately 2,878 education faculty members at twenty public research institutions. The institutions were selected as a purposive sample and represented different regions of the United States with toprated education programs as determined by U.S. News \& World Report ${ }^{8}$ and with libraries that are members of the Association of Research Libraries. The sample was chosen to ensure that the faculty were from institutions of similar size and reputation, which could influence faculty information-seeking behaviors. Student assistants gathered e-mail addresses of all faculty listed on the institutions' websites for their education department or college. This typically included both tenured and nontenured faculty as well as researchers and faculty emeritus; the survey was sent to the entire population as denoted on the institutional websites. Faculty members were given three weeks to respond; a reminder e-mail was sent after two weeks.

\section{Results \& Discussion}

Of the 2,878 e-mail invitations sent, 538 education faculty members responded, for an overall response rate of 18.69 percent. By institution, the response rate ranged from 9.88 percent to 30.85 percent. If fewer than twenty responses were received from an institution, that institution's data were removed from the data set. This left the data from twelve institutions to be included in the analysis.

A chi-square test of association was conducted on the data gathered by eleven of the survey questions to determine the statistical significance, if any, of the relationship between the respondents' institution and the answers given in response to the survey. The results of this analysis are presented in tables 1-9.

Few of the $p$ values indicate a statistically significant $(p \leq 0.05)$ association between a given response and the respondent's institution. This suggests that, for most types of information gathered, the results found at one institution would 


\begin{tabular}{|l|c|c|c|}
\hline \multicolumn{4}{|c|}{ TABLE 1 } \\
Departmental Duties Correlated to \\
Respondents' Institution \\
\hline & $\begin{array}{c}\text { Pearson } \\
\chi 2 \text { Value }\end{array}$ & $d f$ & $p$ \\
\hline Supervision of Doctoral Research & 21.527 & 11 & 0.028 \\
\hline Graduate Instruction & 23.618 & 11 & 0.050 \\
\hline Field and/or Laboratory Research & 19.688 & 11 & 0.050 \\
\hline Undergraduate Instruction & 18.009 & 11 & 0.081 \\
\hline Grant Preparation & 14.707 & 11 & 0.196 \\
\hline Commercial/Proprietary Research & 14.655 & 11 & 0.199 \\
\hline Administrative Duties & 12.999 & 11 & 0.293 \\
\hline
\end{tabular}

"Which of the following are included in your departmental duties?" (see table 1). Overall, the results did not show a systematic difference among the twelve institutions, with the exception of supervision of doctoral research $(p=0.028)$, graduate instruction $(p=0.050)$, and field and/or laboratory research $(p=0.050)$. While the association between institution and responses to this question were not

mirror the results found at another institution when education faculty were asked the same questions. The $p$ values presented in the tables do not indicate the level of importance associated with any of the given services, merely that the answers given were or were not statistically significant in their association to a particular institution.

\section{Departmental Duties}

In the survey, faculty members were asked to provide answers to several demographic questions such as area of specialty within education, their length of time in the field, their institutional rank, and what was included in their departmental duties. Much of this was for the aggregated study on the information-seeking behavior of education faculty and was not analyzed for the purposes of the current study because it was assumed to be (1) institution-specific and (2) readily accessible to librarians at an institution without having to conduct a formal survey.

However, the researchers did perform a chisquare analysis of association on the responses received to the question, statistically significant for the most part, librarians at the institution are best positioned to know the job requirements of their institutions' faculty and should interpret survey results with this knowledge in mind.

\section{Information Use}

The chi-square analysis of the responses received to the question, "How many of the following have you completed within the past 5 years?" indicated that there was no statistically significant association between the responses and the respondents' institution (see table 2).

The researchers asked faculty how frequently they sought information to complete a series of tasks common to

\begin{tabular}{|l|c|c|c|}
\hline \multicolumn{5}{|c|}{ TABLE 2} \\
$\begin{array}{l}\text { Frequency of Completed Research Projects } \\
\text { Correlated to Respondents' Institution }\end{array}$ \\
\hline & $\begin{array}{c}\text { Pearson } \\
\chi 2 \text { Value }\end{array}$ & $d f$ & $p$ \\
\hline $\begin{array}{l}\text { Nonrefereed Journal Articles/ } \\
\text { Book Chapters }\end{array}$ & 59.568 & 44 & 0.059 \\
\hline Conference Proceedings & 55.233 & 44 & 0.119 \\
\hline Books & 48.486 & 44 & 0.297 \\
\hline Grant Applications & 48.342 & 44 & 0.302 \\
\hline Patents/Commercial Projects & 44.986 & 44 & 0.430 \\
\hline $\begin{array}{l}\text { Refereed Journal Articles/ } \\
\text { Book Chapters }\end{array}$ & 44.276 & 44 & 0.460 \\
\hline
\end{tabular}




\begin{tabular}{|c|c|c|c|c|}
\hline \multicolumn{5}{|c|}{$\begin{array}{c}\text { TABLE } 3 \\
\text { Frequency of Information Seeking to Complete Tasks Correlated to } \\
\text { Respondents' Institution }\end{array}$} \\
\hline & $\begin{array}{l}\text { Pearson } \\
\chi 2 \text { Value }\end{array}$ & $d f$ & $p$ & $\begin{array}{c}\text { At Least } \\
\text { Monthly (\%) }\end{array}$ \\
\hline Prepare a New Research Pproposal/Grant Application & 83.677 & 55 & 0.008 & $16.1-39.2$ \\
\hline Professional Development/Remain Current in the Field & 69.832 & 55 & 0.086 & $74.4-87.5$ \\
\hline Prepare for Student Lectures & 61.76 & 55 & 0.247 & $66.7-96.1$ \\
\hline Write/Research for Publication & 61.275 & 55 & 0.261 & $48.6-89.7$ \\
\hline Determine Protocols for Field Research & 57.663 & 55 & 0.377 & $20.8-36.4$ \\
\hline Prepare for a Conference Presentation & 50.745 & 55 & 0.638 & $27.5-56.9$ \\
\hline
\end{tabular}

education faculty members. Five of the six tasks did not show a systematic difference among the institutions. The single statistically significant associated task was preparing a new research proposal/ grant application $(p=0.008)$ (see table 3$)$.

To determine the possible implications for practitioners, the researchers combined responses to look at the range of faculty responses by institution indicating that they sought information to complete a given task at least monthly. When looking at the data in this way, the ranges that seem to indicate a meaningful difference are writing/researching for publication and preparing for a conference presentation. At Arizona State University, only 48.6 percent of the faculty indicated they sought information to write/research for publication at least monthly, whereas 89.7 percent of the faculty at the University of Missouri indicated seeking information for this purpose at least monthly. By contrast, only 27.5 percent of the respondents at the University of Missouri indicated they sought information to prepare for a conference presentation at least monthly, while 56.9 percent of the responding faculty at Texas A\&M indicated seeking information for this purpose at the same frequency. Since each of these tasks requires similar types of information, it is unlikely that these differences would have a significant impact on collection development activities or the disbursement of funds.

\begin{tabular}{|l|c|c|c|c|}
\hline \multicolumn{5}{|c|}{ TABLE 4 } \\
Ranked Importance of Sources for Aiding Research Correlated to \\
Respondents' Institution
\end{tabular}




\begin{tabular}{|l|c|c|c|c|}
\hline \multicolumn{5}{|c|}{ TABLE 5 } \\
Sources for Remaining Current in the Field Correlated with \\
Respondents' Institution
\end{tabular}

\section{Finding Information}

While it is typical for practitioner-researchers to inquire about the productivity of practitioners and the tasks that led them to seek information, knowing where they go to find information once they have an expressed need has more immediate implications for librarians. To determine this, the education faculty members were asked to rank the importance of sources for helping them with their research, for staying current in their field, and for identifying older resources that might be relevant to their needs.

Of the nine resources listed as potentially helping faculty with their research, two were found to be statistically significantly associated to the respondent's institution. Those that were significantly associated include e-mail discussion with students ( $p=0.005)$ and face-to-face discussion with students $(p=0.035)$ (see table 4$)$.

The chi-square analysis of the responses to "How do you keep abreast of current developments in your field?" provided a similar finding. With the exception of personal communication $(p=0.037)$, the overall results did not show a systematic difference among the twelve institutions (see table 5). Only one of the responses to how faculty members became aware of less recent journal articles was statistically significantly associated to the respondents' institutions: using citations at the end of book chapters $(p=0.033$ ) (see table 6).

\begin{tabular}{|l|c|c|c|c|}
\hline \multicolumn{5}{|c|}{ TABLE 6 } \\
Tools Used to Discover Less Recent Journal Articles Correlated with \\
Respondents' Institution \\
\hline & $\begin{array}{c}\text { Pearson } \\
\chi 2 \text { Value }\end{array}$ & $d f$ & $p$ & $\begin{array}{c}\text { Range of } \\
\text { Responses (\%) }\end{array}$ \\
\hline Citations at the End of Book Chapters & 21.045 & 11 & 0.033 & $40.6-81.3$ \\
\hline $\begin{array}{l}\text { Retrospective Searching of Indexing/ } \\
\text { Abstracting Tools }\end{array}$ & 12.408 & 11 & 0.334 & $35.5-62.1$ \\
\hline Browsing through Older Volumes & 12.201 & 11 & 0.349 & $11.4-35.5$ \\
\hline Personal Communication & 10.394 & 11 & 0.495 & $31.3-58.3$ \\
\hline Citations at the End of Journal Articles & 9.191 & 11 & 0.604 & $79.2-96.9$ \\
\hline
\end{tabular}




\begin{tabular}{|l|c|c|c|c|}
\hline \multicolumn{5}{|c|}{ TABLE 7} \\
Factors Limiting Use of Library's Electronic Services/Resources Correlated \\
with Institution
\end{tabular}

The researchers were also interested in the factors influencing a faculty member's choice to use a resource or service and asked three questions related to this. Faculty were asked which factor most influenced their use of a current information source and were given six choices as well as the option to provide their own answer. These choices included: least time to track down the information, convenience, currency, authoritativeness (reliable, complete information), familiarity, and reliably available/no wait or hassle. The faculty members' responses to this question were not found to be statistically significantly tied to the respondents' institution $(d f=66, p=0.436)$.

Respondents were asked to indicate which factors might limit their use of the library's electronic services and resources and were allowed to select all that applied. Of the seven choices, only two were found to be statistically significantly associated to the respondents' institutions - hard to find on library website $(p=0.022)$ and unavailability of needed electronic resources/services $(p=0.048)$ (see table 7). It stands to reason that these factors would be influenced by a faculty member's home institution, given that subscriptions and library websites are specific to the institution whereas access restrictions and lack of time are likely more ubiquitous.

Faculty were asked how the library's electronic resources and services improve finding needed information and were allowed to select all that applied (see table $8)$. Only one choice-provides access to full text publications $(p=0.038)$ - was found to be statistically significantly associated to the respondents' institution. While the $p$ value indicates the response variation is statistically significantly tied

\begin{tabular}{|l|c|c|c|c|}
\hline \multicolumn{7}{|c|}{ TABLE 8 } \\
\hline \multicolumn{2}{|c|}{ Benefits of Electronic Resources/Services Correlated with Institution } \\
\hline & $\begin{array}{c}\text { Pearson } \\
\chi 2 \text { Value }\end{array}$ & $d f$ & $p$ & $\begin{array}{c}\text { Range of } \\
\text { Responses (\%) }\end{array}$ \\
\hline Provides Access to Full-text Publications & 20.605 & 11 & 0.038 & $54.2-92.2$ \\
\hline $\begin{array}{l}\text { Helps me Assist Students in their Research } \\
\text { Efforts More Effectively }\end{array}$ & 14.288 & 11 & 0.217 & $41.7-74.2$ \\
\hline Speeds up Research Process & 6.756 & 11 & 0.818 & $79.6-100$ \\
\hline Allows Working from my Office/Home & 6.148 & 11 & 0.863 & $87.5-96.9$ \\
\hline Does Not Improve Finding Information & 5.247 & 11 & 0.919 & $0-3.9$ \\
\hline
\end{tabular}


to the respondents' institution, the range of responses indicates that a majority of the respondents at each institution felt that providing access to the full text of a publication was a benefit of electronic resources. For a practitioner, this would indicate that full text of publications is beneficial to faculty, not just speedier access to resources or out-of-library access to the tools.

\section{Using the Library}

As practitioners, it is important to know the relative value faculty place on various library services. Libraries may be adept at providing a certain service that is of little value to faculty, and knowing this can guide librarians in allocating finite resources and staff time better. The education faculty were asked a general question about the importance of library research in their field, with the answer choices including very important, important, neutral, unimportant, or not applicable. The chi-square analysis of the responses indicated that they were not statistically significantly tied to the respondents' institution ( $d f=11, p=0.647)$.

The education faculty were asked to rate ten library services as very important, important, neutral, unimportant, or not applicable to their needs (see table 9). With regard to the importance education faculty members place on various library services, there seems to be a distinction between physical space, the services themselves and providing access to resources. Regardless of institution surveyed, researchers are likely to get similar results when asking about the importance faculty place on libraries providing access to electronic journals, physical or electronic books, and databases. However, the value faculty place on services such as document delivery $(p \leq 0.001)$ and interlibrary loan $(p=0.020)$ is statistically significantly tied to their home institution.

To better understand this difference, figures 1, 2, and 3 show the percentage of faculty indicating the importance they place on document delivery, library subscriptions to scholarly journals in print, and space to study and conduct research by institution. Responses of important and very important were combined, as were responses of unimportant and not applicable, because the researchers felt these responses would have similar implications for practitioners. It is interesting to note that the importance faculty place on document delivery was shown

TABLE 9

Ranked Importance of Library Services in Meeting Information Needs Correlated to Respondents' Institution

\begin{tabular}{|l|c|c|c|c|}
\hline & $\begin{array}{c}\text { Pearson } \\
\chi 2 \text { Value }\end{array}$ & $d f$ & $p$ & $\begin{array}{c}\text { Very Important } \\
\text { + Important (\%) }\end{array}$ \\
\hline Document Delivery & 82.887 & 44 & 0.000 & $39.0-91.3$ \\
\hline Interlibrary Loan & 65.368 & 44 & 0.020 & $53.7-95.7$ \\
\hline Assistance from Library Personnel & 59.836 & 44 & 0.056 & $40.7-79.3$ \\
\hline E-access to Archives of Scholarly Journals & 42.237 & 33 & 0.130 & $91.6-100$ \\
\hline E-access to Current Scholarly Journals & 41.468 & 33 & 0.148 & $94.6-100$ \\
\hline Print Subscriptions to Scholarly Journals & 51.237 & 44 & 0.211 & $35.5-78.0$ \\
\hline Library Databases (e.g. ERIC) & 36.373 & 33 & 0.314 & $80.9-100$ \\
\hline Physical Book Collection & 45.585 & 44 & 0.406 & $59.4-83.8$ \\
\hline E-book Collection & 42.575 & 44 & 0.533 & $57.1-86.6$ \\
\hline Space to Study/Conduct Research & 42.013 & 44 & 0.557 & $25.8-42.8$ \\
\hline
\end{tabular}




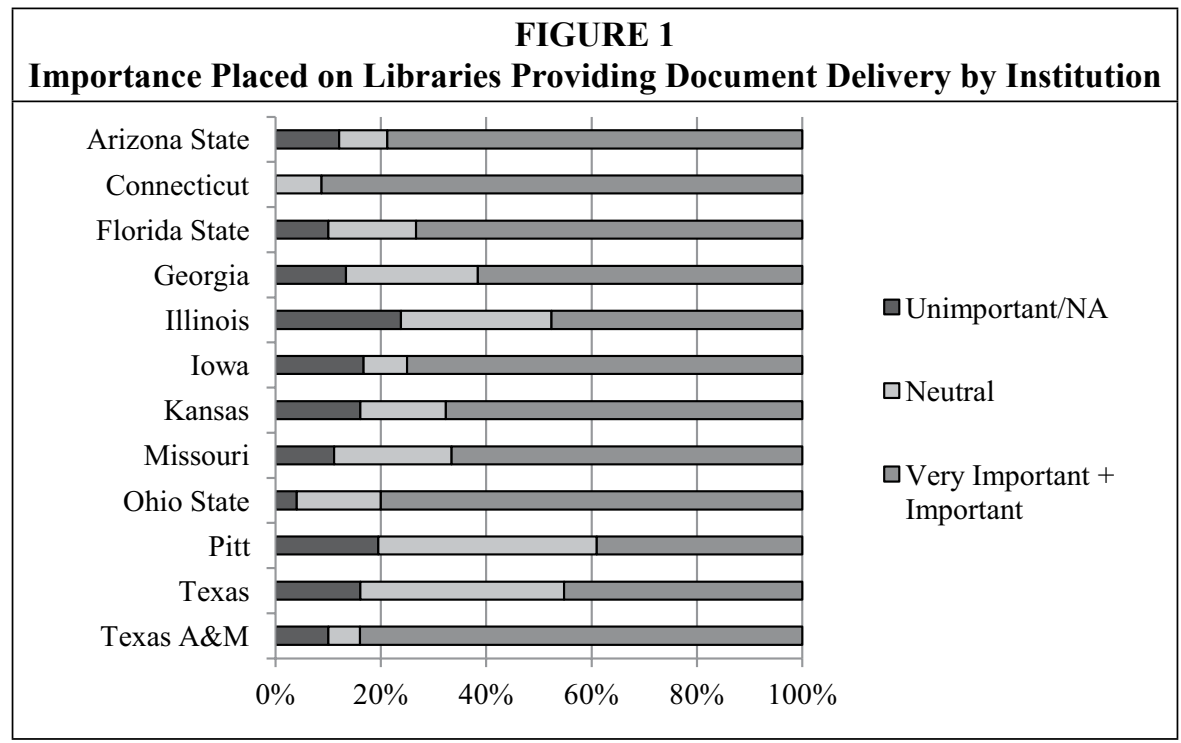

to be statistically significantly associated to institution $(p \leq 0.001)$. Yet, looking at the responses by institution when the percentage rating the service "very important" and "important" are combined, it appears to matter very little which institution is surveyed-the response would indicate that document delivery is an important library service. Pitt faculty had the smallest percentage of respondents rating document delivery as important, with only 39.0 percent rating it as either very important or important; only 19.0 percent of their faculty indicated it was unimportant or not applicable, so many remained neutral on the topic.

Figure 2 depicts the percentage of faculty indicating the importance they place on libraries providing access to print journals by institution. The importance faculty

\begin{tabular}{|r|r|r|r|r|r|}
\hline & \multicolumn{5}{c|}{ FIGURE 2 } \\
Importance Placed on Libraries Providing Access to Print Journals \\
by Institution
\end{tabular}


place on libraries providing access to print journals was not shown to be statistically significantly associated to institution $(p=0.221)$. This suggests that, regardless of the institution surveyed, researchers could expect to receive similar results. However, a look at figure 2 tells a somewhat different story. If, for example, the study was conducted solely at the University of Kansas, one might get the impression that faculty minimally value print access to journals, with only 35.5 percent of the respondents indicating it was very important or important. By contrast, if the study had been conducted solely at Pitt, it would appear that education faculty still place a high value on print journals, with 78.0 percent rating it as very important or important. The difference in these findings would have entirely different implications for the allocation of collection development funds. At institutions where print is still highly valued, the cancellation of print subscriptions in favor of electronic would require greater preparation among library constituents; however, at institutions where print is deemed less important, librarians might easily be able to shift spending away from print subscriptions if they have not already done so.
Figure 3 paints a similar picture; the importance faculty place on libraries providing a space to study and conduct research was not shown to be statistically significantly associated to institution $(p=0.557)$. Again, while the chi-square analysis indicates that, regardless of the institution surveyed, researchers could expect to receive similar results, the results themselves suggest otherwise. Of the twelve institutions included in the study, three had a greater percentage of faculty indicating space to study or conduct research was important or very important than indicating it was unimportant or not applicable. The University of Missouri had the most faculty members indicating library space was important to them, with 42.8 percent of the faculty rating it as either important or very important; however, 21.4 percent of Missouri's faculty rated it as either unimportant or not applicable. At the University of Iowa, 30.4 percent of faculty members rated library space to study or conduct research as important, while 60.8 percent rated it as unimportant or not applicable. This suggests that the extent of importance varies by institution, but the fact that no institution had a majority of faculty members

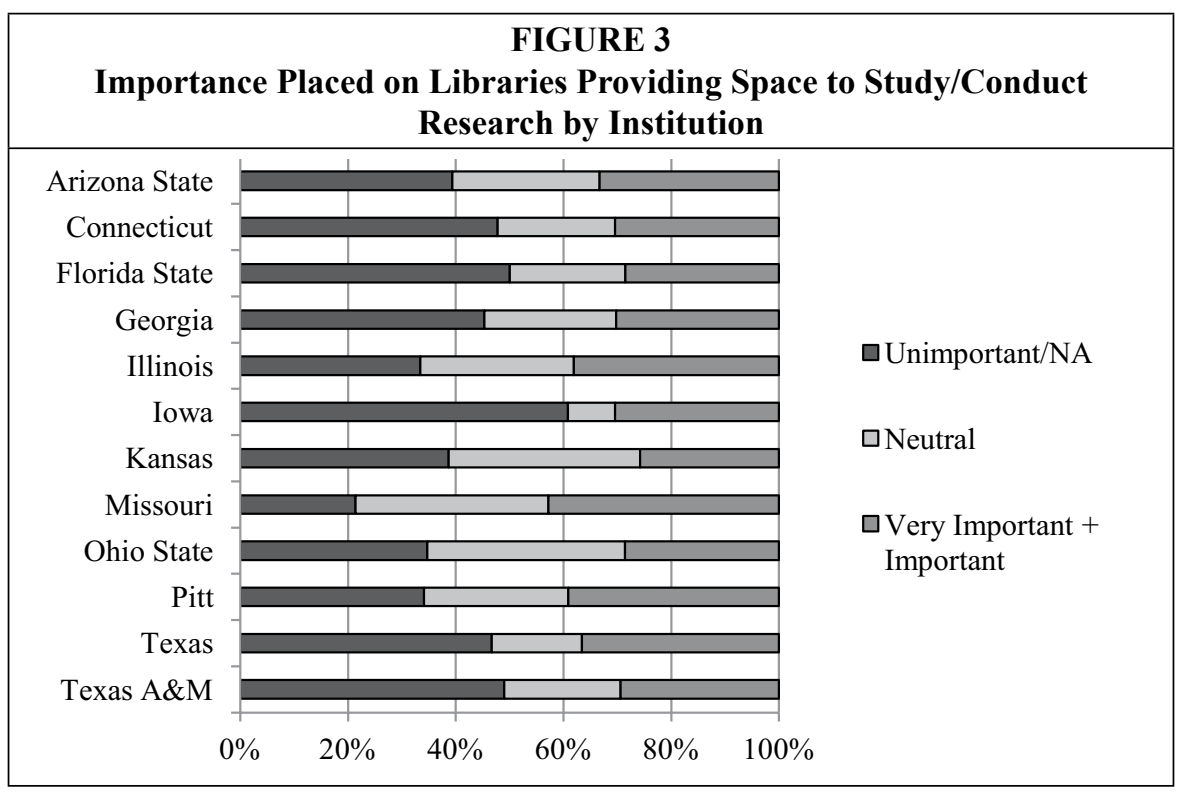




\begin{tabular}{|c|c|c|c|c|c|c|}
\hline \multicolumn{7}{|c|}{$\begin{array}{c}\text { TABLE } 10 \\
\text { Frequency of Information Seeking to Complete Tasks Correlated to } \\
\text { Respondents' Institution Compared by Discipline }\end{array}$} \\
\hline & \multicolumn{3}{|c|}{ Education Faculty } & \multicolumn{3}{|c|}{ Engineering Faculty } \\
\hline & $\begin{array}{l}\text { Pearson } \\
\chi 2 \text { Value }\end{array}$ & $d f$ & $p$ & $\begin{array}{l}\text { Pearson } \\
\chi 2 \text { Value }\end{array}$ & $d f$ & $p$ \\
\hline $\begin{array}{l}\text { Prepare a New Research Proposal/Grant } \\
\text { Application }\end{array}$ & 83.677 & 55 & 0.008 & 82.022 & 75 & 0.271 \\
\hline $\begin{array}{l}\text { Professional Development/Remain } \\
\text { Current in the Field }\end{array}$ & 69.832 & 55 & 0.086 & 102.010 & 75 & 0.021 \\
\hline Prepare for Student Lectures & 61.76 & 55 & 0.247 & 63.855 & 75 & 0.817 \\
\hline Write/Research for Publication & 61.275 & 55 & 0.261 & 103.353 & 75 & 0.017 \\
\hline Determine Protocols & 57.663 & 55 & 0.377 & 68.415 & 75 & 0.691 \\
\hline Prepare for a Conference Presentation & 50.745 & 55 & 0.638 & 98.936 & 75 & 0.034 \\
\hline Research Patents & \multicolumn{3}{|c|}{ Not Available } & 81.065 & 75 & 0.296 \\
\hline
\end{tabular}

indicating space for study and research was highly valued that the data found at one institution may indeed be "good enough" for other institutions.

\section{A Tale of Two Studies}

As indicated in the methodology, this study replicates a study conducted on engineering faculty in the fall of 2009 and is meant to test whether the findings of the initial study hold true in a different discipline. By comparing the data between the studies, it is possible to begin to determine what types of questions asked in singleinstitution user studies can be accepted as descriptive of an equivalent population at other, similar institutions.

\section{Information Use}

In both studies, the researchers asked how frequently the faculty members sought information to complete a series of tasks. For the engineering faculty, the frequency with which faculty sought information to complete three of the six listed tasks was statistically significantly associated to institution; for the education faculty, only one of the tasks was statistically significantly associated to institution (see table 10). In both studies, the researchers then looked at the range of the percentage of faculty reporting doing these activities at least monthly. They found that the ranges were not so wide that a practitioner would draw differing conclusions on the population based on the results at any single institution. For this particular question, the types of information sources a faculty member would need to perform most of these tasks are quite similar; so if a majority of faculty indicate they are seeking information for any one of these tasks, practitioners are likely to feel validated in their ongoing collection development activities.

\section{Finding Information}

In both studies, faculty were asked to rank the importance of a list of sources for aiding their research. For engineering faculty, the ranked importance of three sources was statistically significantly associated with the respondents' institution, while that was the case for only two of the sources for education faculty (see table 11). However, for this question, the two showing a statistically significant association for the education faculty were also statistically significant for the engineering faculty, and both had to do with facultystudent communication.

This theme resonates in responses to the next question faculty answered in regard to the sources they use to remain 


\begin{tabular}{|l|c|c|c|c|c|c|}
\hline \multicolumn{7}{|c|}{ TABLE 11 } \\
\begin{tabular}{|l} 
Ranked Importance of Sources for Aiding Research Correlated to \\
Respondents' Institution Compared by Discipline
\end{tabular} \\
\hline & \multicolumn{3}{|c|}{ Education Faculty } \\
\hline & $\begin{array}{c}\text { Pearson } \\
\chi 2 \text { Value }\end{array}$ & $d f$ & $p$ & $\begin{array}{c}\text { Pearson } \\
\chi 2 \text { Value }\end{array}$ & $d f$ & $p$ \\
\hline E-mail Discussion with Students & 57.466 & 33 & 0.005 & 62.173 & 45 & 0.046 \\
\hline Face-to-face Discussion with Students & 49.197 & 33 & 0.035 & 64.360 & 45 & 0.031 \\
\hline Attendance at Conferences & 45.445 & 33 & 0.073 & 62.318 & 45 & 0.044 \\
\hline Face-to-face Discussion with a Colleague & 36.875 & 33 & 0.294 & 50.597 & 45 & 0.260 \\
\hline E-mail discussion with a Colleague & 36.247 & 33 & 0.320 & 47.498 & 45 & 0.371 \\
\hline Internet Resources & 33.745 & 33 & 0.431 & 61.466 & 45 & 0.052 \\
\hline Books & 33.626 & 33 & 0.437 & 61.466 & 45 & 0.052 \\
\hline Scholarly Journals (in print/online) & 33.109 & 33 & 0.462 & 41.088 & 45 & 0.638 \\
\hline Textbooks & 29.235 & 33 & 0.655 & 42.685 & 45 & 0.570 \\
\hline
\end{tabular}

current in their field. For both engineering and education faculty, personal communication was the only response statistically significantly associated to institution (education faculty: $d f=11, p=0.037$; engineering faculty: $d f=15, p=0.001$ ). From a practitioner standpoint, these findings have little implication for day-to-day library work unless the library makes an effort to actively foster relationships among departmental faculty and students.

Next, faculty in each study were asked which tools they use to discover less recent journal articles. For the engineering faculty, no tools were statistically significantly associated with the institution, and only one tool, citations at the end of book chapters, was statistically significantly associated for education faculty $(d f=11$, $p=0.033$ ). From a practitioner standpoint, a library is going to continue to order books, in some format, regardless of whether or not faculty are using the citations at the end of book chapters to locate older materials. Since this is not a primary purpose for ordering books, it seems that a library's collection development policy would not be changed based on this discovery, regardless of whether only 40.6 percent of faculty indicated using this method of discovery in a study. Knowing that faculty do or do not use citations at the end of book chapters to become aware of less current journal articles might inform instruction practices; but, again, if a librarian covers citation tracking in an instruction session, it would likely be a part of a larger lesson on citation tracking in general, regardless of whether the citations come from a book or journal.

\section{Using the Library}

In all likelihood, practitioners conducting similar studies at their institutions are most interested in how their library is meeting the users' needs and how services might be improved. To this end, faculty in both studies were asked to rank the importance of library services in meeting their information needs. In each study, there was a marked difference in responses for collections, space, and services. For both studies, document delivery and interlibrary loan were statistically significantly associated to institution, while the ranked importance of resources and library facilities were not statistically significantly associated to institutions (see table 12). This seems to imply that, for the most part, one could trust the data from a study conducted at an institution similar to one's own. 
However, the researchers for each study highlighted responses by institution for several of the listed services to aid in understanding the dangers in relying solely on another institution's data for decision making. In the study of engineering faculty, the researchers note:

If, for example, the study was conducted solely at UCLA, one might get the impression that more faculty find library assistance unimportant or not applicable than find it important (though $42.8 \%$ of the UCLA respondents remained neutral on the topic). This finding might call into question the necessity of reference departments at engineering libraries across the country. By contrast, if the study had been conducted at the University of Oklahoma, the results would suggest that assistance from library personnel was considered important to the majority of engineering faculty $(63.4 \%)$ and have entirely different implications for practitioners. $^{9}$
This difference has strong implications for practice and indicates that librarians should be cautious consumers of research studies and validate the findings locally when feasible, especially when great stakes are concerned.

\section{Conclusion}

After the previous study of engineering faculty, the researchers questioned the applicability of the findings to practitioners. Regardless of whether data gathered at one institution was comparable to similar populations at similar institutions, how could the data be used to inform practice and assist with decision making? This study used a modified survey instrument in hopes of providing more useful information for practitioners while maintaining many of the original questions for the sake of comparison.

The findings of the current study of education faculty confirmed the findings of the previous study of engineering faculty. For the most part, responses to questions related to general productivity, duties, and preferred sources are not

\begin{tabular}{|l|c|c|c|c|c|c|}
\hline \multicolumn{7}{|c|}{ TABLE 12 } \\
Ranked Importance of Library Services in Meeting Information Needs \\
Correlated to Respondents' Institution by Discipline \\
\hline & \multicolumn{2}{|c|}{ Education Faculty } & \multicolumn{2}{c|}{ Engineering Faculty } \\
\hline & $\begin{array}{c}\text { Pearson } \\
\chi 2 \text { Value }\end{array}$ & $d f$ & $p$ & $\begin{array}{c}\text { Pearson } \\
\chi 2 \text { Value }\end{array}$ & $d f$ & $p$ \\
\hline & 82.887 & 44 & 0.000 & 108.881 & 60 & 0.000 \\
\hline Document Delivery & 65.368 & 44 & 0.020 & 127.392 & 60 & 0.000 \\
\hline Interlibrary Loan & 59.836 & 44 & 0.056 & 72.878 & 60 & 0.123 \\
\hline Assistance from Library Personnel & 42.237 & 33 & 0.130 & 57.777 & 60 & 0.557 \\
\hline $\begin{array}{l}\text { E-access to Archives of Scholarly } \\
\text { Journals }\end{array}$ & & & & & & \\
\hline E-access to current Scholarly Journals & 41.468 & 33 & 0.148 & 57.171 & 60 & 0.580 \\
\hline $\begin{array}{l}\text { Print Subscriptions to Scholarly } \\
\text { Journals }\end{array}$ & 51.237 & 44 & 0.211 & 73.601 & 60 & 0.112 \\
\hline Library Databases & 36.373 & 33 & 0.314 & 72.005 & 60 & 0.138 \\
\hline Physical Book Collection & 45.585 & 44 & 0.406 & 54.691 & 60 & 0.669 \\
\hline E-book Collection & 42.575 & 44 & 0.533 & 49.970 & 60 & 0.819 \\
\hline Space to Study/Conduct Research & 42.013 & 44 & 0.557 & 70.777 & 60 & 0.161 \\
\hline Access to Laboratory Protocols & \multicolumn{7}{|c|}{ Not Available } & 81.735 & 60 & 0.033 \\
\hline
\end{tabular}


institution-specific. Librarians could rely on the data from a single-institution study to develop a better understanding of their own faculty's information-seeking behaviors in a given discipline, provided the institutions are similar in size and research focus. Responses to questions about why faculty seek information and how they go about finding it were also fairly consistent among the various institutions.

However, as common sense would seem to dictate, librarians should use caution when relying on others' data for highly institution-specific areas such as services provided or strengths and weaknesses in resource availability. The areas where there were the most statistically significant associations between responses and institutions related to areas with fairly clear local ties such as accessing items via an institutional website and services such as interlibrary loan or reference assistance. Essentially, librarians should proceed with caution and seek to validate findings locally when the stakes are high.

This study is the second of many needed to fully understand how to make survey results from information-seeking behavior studies relevant to practitioners. The researchers intend to further finetune the survey instrument to collect information that is meaningful to practitioners and then conduct future multiinstitutional studies that examine faculty and/or students in other disciplines such as the humanities, fine arts, and/or life sciences. Given the inherent limitations of a purposive sample, it might also be beneficial to repeat the current study within the fields of education and engineering with a random sample of faculty at large research institutions.

\section{Notes}

1. Virginia Wilson, "Applicability: What Is It? How Do You Find It?" Evidence Based Library and Information Practice 5, no. 2 (2010), available online at http://ejournals.library.ualberta.ca/index. php/EBLIP/article/view/8091 [accessed 4 August 2011].

2. Ibid., 112.

3. Ray Lyons, "Statistical Correctness," Library \& Information Science Research 33 (2011): 92-95.

4. Elke Greifeneder and Michael S. Seadle, "Research for Practice: Avoiding Useless Results," Library Hi Tech 28, no. 1 (2010): 5-7.

5. Ibid., 7.

6. Lili Luo, "Fusing Research into Practice: The Role of Research Methods Education," Library E Information Science Research 33 (2011): 191-201.

7. Sarah Robbins, Debra Engel, and Christina Kulp, “How Unique Are Our Users? Comparing Responses Regarding the Information-Seeking Habits of Engineering Faculty," College \& Research Libraries 72, no. 6 (2011): 515-32; Maria A. Jankowska, "Identifying University Professors' Information Needs in the Challenging Environment of Information and Communication Technologies," Journal of Academic Librarianship 30, no. 1 (2004): 51-66; Anita Cannon, "Faculty Survey on Library Research Instruction," RQ 33, no. 4 (1994): 524-41.

8. Accessed online at http://grad-schools.usnews.rankingsandreviews.com/best-graduateschools/top-education-schools during July 2010.

9. Robbins, Engel, and Kulp, "How Unique Are Our Users?" 526. 